\title{
Intercultural competence and intercultural communication in the context of education for sustainable development
}

\author{
Marina Nikiforova, and Irina Skvortsova \\ Ural State University of Economics, 8 Marta/Narodnoy Voli St. 62/45, 620144 Yekaterinburg, Russia
}

\begin{abstract}
The paper discusses the essence of intercultural competence in the light of transition to education for sustainable development. The authors provide critical review of the concept of intercultural competence and its components. The interrelation of intercultural and linguistic competences in higher education has been reevaluated. Special attention has been given to Intercultural Communication as an academic discipline. The authors stress the importance of developing intercultural competence as an integral part of University education.
\end{abstract}

\section{Introduction}

The concept of sustainable development, adopted in 1992 in Rio de Janeiro at the UN Conference, is basically described as a triad of economic, ecological and social components. Education is rightly considered as one of the most significant constituents of the social subsystem. The UNESCO website stresses that UNESCO organization "aims to improve access to quality education on sustainable development at all levels and in all social contexts, to transform society by reorienting education and help people develop knowledge, skills, values and behaviours needed for sustainable development"[1].

Education in terms of sustainable development has a global focus and is meant to help students respond adequately to fundamental challenges of the modern world that we all as humans have to face today - increasing economic inequality, healthcare problems, climate change, etc. Thus, when speaking about the system of higher education - both in the global context and in the Russian Federation, which is actively integrating into the international educational space - scholars and educators admit that an effective and painless transition to the model of education for sustainable development in the contemporary setting can take place only if the appropriate legal framework is established, which implements the sustainable development principles in education standards and education programmes. Thus, the whole system of higher education is to be (re)focused on humanitarian values and ideals of the civilization, on global objectives and priorities of the sustainable world. Most important, the crucial competences (professional and supra-professional) of a future specialist should be and actually are being reconsidered. Among them is intercultural competence, which is normally included into a complex of various communication skills, but in the context of education for sustainable development it takes on a special significance. 
In this paper we aim to highlight the essence of intercultural competence in higher education, to discuss the importance of developing intercultural attitudes and communication skills required for multicultural interaction. We also stress the importance of learning and teaching Intercultural Communication as a University course in education programmes of all majors. Learning about other cultures and understanding your own one can lead to more empathy and tolerance and can help facilitate multicultural interaction on the way to sustainable future.

\section{Materials and methods}

The key methods of study used in the paper are critical review of theoretical materials and other scholars' findings, pedagogical observation and reflection on our own experiences in Foreign Language and Intercultural Communication teaching at the Department of Business Foreign Language of Ural State University of Economics (Yekaterinburg, Russia). We also provide some findings of our own as to designing and conducting a course of Intercultural Communication to third-year students, majoring in World Economics and International Management.

\section{Results and discussion}

\subsection{The essence of intercultural competence in the light of transition to education for sustainable development}

Intercultural scholars put forward various definitions of intercultural competence (intercultural communicative competence, or ICC). Among the most cited definitions is the one, which claims that intercultural competence is "the ability to communicate effectively and appropriately in intercultural situations based on one's intercultural knowledge, skills, and attitudes" [2].

In regard to specific constituents of intercultural competence, scholars also stress various components and characteristics. Thus, in the pyramid model of intercultural competence provided by D. K. Deardorrf [ibid], the fundamental basis of intercultural competence is made up of requisite attitudes (valuing other cultures, cultural diversity, openness to intercultural learning and to people from other cultures, withholding judgment, tolerating ambiguity and uncertainty). The second layer of the pyramid is formed by knowledge \& comprehension (cultural self-awareness, deep understanding and knowledge of culture, culture-specific information, and sociolinguistic awareness) and skills (to listen, observe, and interpret; to analyze, evaluate, and relate). The two top layers of the pyramid are made up of desired internal and external outcomes. The internal outcome involves such personal traits and characteristics as adaptability to different communication styles and behaviors, adjustment to new cultural environments, flexibility in using appropriate communication styles and behaviors, cognitive flexibility, ethnorelative view; empathy. The external outcome suggests the ability to behave and communicate effectively and appropriately to achieve one's goals to some degree.

R. D. Lambert highlights the five components of intercultural competence: world knowledge, foreign language proficiency, cultural empathy, approval of foreign people and cultures, ability to practice one's profession in an international setting" [3].

M. Byram stresses such components of intercultural competence as "knowledge of others; knowledge of self; skills to interpret and relate; skills to discover and/or to interact; valuing others' values, beliefs, and behaviors; and relativizing one's self. Linguistic competence plays a key role"[4]. 
According to K. McLoud-Schingen, "communicating effectively across cultures requires curiosity, empathy, compassion, and a strong sense of self" [5].

Thus, while some scholars tend to overlook the importance of foreign language proficiency, others ascribe special significance to it. We believe such differences are caused by the approach different interculturalists apply - whether intercultural competence is perceived as a secondary ability in relation to purely communicative competence or as the one comprising language proficiency and intercultural knowledge, skills, and attitudes in their holistic entity.

From our viewpoint, this is a rather challenging issue - how to better define and evaluate intercultural competence in terms of higher education goals and objectives. On the one hand, when defining intercultural competence, educators should not neglect the language proficiency component, because any communication can take place only when certain meanings are communicated, when the interlocutors understand and make themselves understood. On the other hand, communication between people of various cultural backgrounds does not necessarily occur in the mother tongue of one of the interlocutors; it can also happen and it oftentimes does happen in the intermediary language, such as English, Chinese, etc. From this perspective, intercultural competence and foreign language proficiency as such can be differentiated, though not separated. Even if we admit that intercultural competence cannot be limited only to developing the linguistic competence, or teaching how to use various forms and patterns of speech in a target language, we also have to admit that intercultural competence developing is a long and complicated process, which starts not in higher education, but a lot earlier, that is when one only starts learning a foreign language. In fact, in today's language education, we can observe an emphasis shift from exclusively pragmatic tasks in learning and teaching a language, when the latter is understood as a merely utilitarian value, to developing a learner's ability to comprehend a different mindset, a different ideology, a different set of values and world views. In other words, modern language education is focused not only on forming and developing the learner's ability to practically use the language in various communicative contexts (i.e. communicative skills development), but also on developing respectful and tolerant attitude towards the target language culture. And this is already what we refer to as constituents of intercultural communicative competence.

Yet, in higher education, intercultural competence has a more global focus and goes far beyond the ability to communicate in the context of the target language culture. From our perspective, developing intercultural competence in higher education should address linguistic competence (foreign language(s) proficiency), meta-communicative competence (the ability to communicate about communication), and a complex of some general and specific knowledge, skills and attitudes, noted by the abovementioned and other top intercultural scholars across the globe [2-13].

Of the specific components noted, there are a few we would like to particularly stress. They are self-awareness and other-sensitivity [5]. To speak about these phenomena, intercultural scholars also use such terms as cultural self-awareness and ethnorelative view [2], knowledge of self and knowledge of others [4], cultural empathy [3] and others. Whatever terminology is applied, at the heart of the phenomena is the basic dichotomy of the world - differentiation between us and them, sameness and otherness, ingroups and outgroups. Identifying with ingroups is a human's natural necessity; it provides senses of security, belonging and comfort. Yet, overemphasizing and overgeneralizing the differences between ingroups and outgroups can lead to stereotypes, prejudice, and bias. As $\mathrm{K}$. McLoud-Schingen rightly notes, "there is a natural instinct to separate the world into us and them, and eventually discriminate against them" [5]. Thus, in the light of transition to education for sustainable development, we believe that intercultural competence is exactly about developing a better understanding of oneself and of various cultural differences. This 
self-awareness and other-sensitivity can help university students avoid prejudice and bias in communication in both labour and social frameworks. Intercultural competence is about using the maxim Not Wrong- Just Different, which according to S. J. Kulich, "can help us try to understand the cultural logics that may be behind the noticeable differences of certain cultural groups" [6]. And this is crucial to intercultural competence from the attitudinal and knowledge perspective. Only when there is a deep understanding and respect towards one's own and others' values, beliefs, and behavioral patterns, effective intercultural communication can take place, which in its turn is meant to contribute to solving many of the global problems and build the planet's sustainable future.

\subsection{Intercultural Communication as an academic discipline: objectives, contents, outcomes}

As it has been mentioned above, we are convinced that in the context of education for sustainable development intercultural competence should be considered as an obligatory competence of any future professional, regardless of majors and education programmes. Yet, for students on such University programmes as International Relations, World Economics or whatsoever programmes, the goal of which is to train specialists to be able to effectively perform at the international level, - intercultural competence takes on special significance, becoming a matter of future professional suitability. Therefore, it is important that intercultural competence as one of purely professional competences should be developed, boosted and assessed within a specific University course - Intercultural Communication. The name of the course can be altered to Crosscultural Comminication(s), and Business Correspondence as part of professional intercultural interaction is sometimes integrated into the course, too.

The objectives of the course are oftentimes generalized and may include

1. developing knowledge and competences aimed at creating a systematic understanding of the main criteria and factors of effective intercultural interaction,

2. enhancing business communication skills in an intercultural environment,

3. developing universal and professional skills, including of how to use intercultural communications in solving professional problems in the field of the world economics and international management.

It is clear that the contents of the course may vary by the education programmes and primarily depend on the course load and allocated contact hours. Yet, given the findings of top intercultural scholars (E.T. Hall, R. Lewis, G. Hofstede, S. J. Kulich, etc) and our own experiences in the field, we are convinced that the course should necessarily include some fundamental intercultural issues and topics, the degree of each topic elaboration depending on the course load.

Thus, the following intercultural issues are to be highlighted and practiced:

-culture and its typologies; high-context and low-context cultures (E.T. Hall), monoactive, polyactive, and reactive cultures (R. Lewis); stereotypes and national character; mechanisms of stereotyping;

-communication and its types; activity theory as a methodological basis for communication theory; communication as a two-way process in interpersonal and intercultural contexts; the communicative act structure; feedback; verbal and nonverbal communication; oral and written forms of communication; types of speech activity: speaking, listening, writing, reading;

-problems of understanding; perception and its main determinants; communication barriers in intercultural communication (technical, physiological, psychological, social, cultural and national); 
- specifics of intercultural communication: differences in traditions, norms, values; factors that reduce risks of communication failures in intercultural communication and ways to overcome communication barriers;

- communication styles: high-context and low-context; a culturally determined attitude to time planning; managing international teams;

- cultural variations in performing business presentations; silence and partial inclusion in the dialogue; speech perception styles (listening skills in different cultures); understanding politeness in different national business cultures; formalities and communication norms;

-nonverbal communication; paralinguistic tools (intonation, strength, volume, timbre, speed of speech, pauses); tactical means of communication (dynamic touches in the form of handshakes, pats); proxemics (distance between interlocutors, communication zones); different cultural attitudes to eye contact; chromatics and differences in color interpretation; kinesics, pantomimics, gestures; cultural differences in the perception of nonverbal means of communication;

- national peculiarities of negotiations; international culture of negotiations and their specifics in the countries of the West and the East;

- the Hofstede model parameters that determine the quantitative characteristics of national cultures: distancing of power, avoidance of uncertainty, individualism/collectivism, masculinity/femininity, long-term/short-term time orientation and self-indulgence/restraint; comparison of cultures based on the Hofstede model; applying parametric measurements of national cultures and determining the place of different countries within these measurements; analyzing the specifics of intercultural communication using the theory of cultural dimensions.

Reflecting on our own experience in designing and conducting Intercultural Communication at Ural State University of Economics and given the feedback from our students on completion of the course, we can state that in terms of learning outcomes Intercultural Communication is important because it

a) delivers specific knowledge of cultural differences,

b) develops a better understanding of self and others,

c) contributes to developing such personal attributes as empathy and openness,

d) enhances specific business intercultural skills of students,

e) has the potential to improve foreign language performance of students.

Thus, Intercultural Communication as a University course can be beneficial for students from many perspectives. And regarding our assessment of the students' intercultural competence (via observation, pre-/posttests, student's papers, presentations and projects, students' interviews, etc), the course proves to be highly effective in the development of various intercultural skills and attitudes, which are meant to further the students' performance both in labour and social frameworks.

\section{Conclusions}

Given the literature research into intercultural competence and our own practical experience in Foreign Language and Intercultural Communication teaching, we can draw the following conclusions.

1. Intercultural competence can be briefly defined as the ability to communicate effectively and appropriately across cultures. As any other competence, especially viewed from the perspective of higher education, it can be considered as a complex of general and specific knowledge, skills and attitudes, linguistic competence being integral into developing intercultural competence. 
2. From the perspective of attitudes and knowledge, intercultural competence implies a deep understanding of one's own cultural identity and being aware of others' cultural identities, as well as of existing cultural differences, and thus, being able to effectively perform at the intercultural level with due respect, openness, and tolerance.

4. Intercultural competence is one of the key supra-professional competences of any future specialist, regardless of majors and education programmes. It is meant to facilitate international contacts and contribute to solving most of the global problems, facing us as human beings.

5. Intercultural competence as a professional competence includes linguistic competence (foreign language(s) proficiency), meta-communicative competence and a complex of specific knowledge, skills and attitudes, meant to facilitate the student's professional performance in intercultural interaction.

Summing it all up, we should stress once again that in order to make an effective transition to the new model of education for sustainable development, the Russian higher education in its contemporary value paradigm, should focus on humanitarian values of the civilization, on global goals, problems and principles of the sustainable world. On that account, intercultural competence (whether professional or supra-professional one) is becoming crucial to developing and disseminating humanitarian values across nations and cultures.

\section{References}

1. UNESCO, Education for Sustainable Development, https://en.unesco.org/

2. D. K. Deardorff, JSIE, 3, 241 (2006)

3. M. Byram, Teaching and assessing intercultural communicative competence (1997)

4. R. D. Lambert, Educational exchange and global competence (1994)

5. K. McLoud-Schingen, The SAGE Encyclopedia of Intercultural Competence, 691 (2015)

6. S. J. Kulich (2015), https://www.futurelearn.com/

7. S. J. Kulich, M. H. Prosser, L. P. Weng, Intercultural research, 4, 33 (2012)

8. S. J. Kulich, The encyclopedia of communication theory, 2, 984 (2009)

9. N. M. Sussman, IJIR, 25, 109 (2001)

10. S. Bochner, Online Readings in Psychology and Culture, 1 (2003)

11. G. Trager, E. T. Hall, Culture as Communication: A Model and Analysis (1954)

12. S. A. McLeod (2008), www.simplypsychology.org/

13. GEERT HOFSTEDE, https://geert-hofstede.com 